\title{
Studies on Ciliary Dyskinesia Factor in Cystic Fibrosis. I. Bioassay and Heterozygote Detection in Serum
}

\author{
James H. Conover ${ }^{[18]}$, Richard J. Bonforte, Peter Hathaway, Sophie Paciuc, Elaine J. Conod, \\ Kurt Hirschhorn, and Frederick B. Kopel \\ Division of Medical Genetics, Department of Pediatrics, Mount Sinai School of Medicine of the City University \\ of New York, New York, New York, USA
}

\section{Extract}

We have modified Spock's rabbit tracheal bioassay to the extent that it is reproducible and reliable for the detection of the cystic fibrosis (CF) gene in single or double dose from serum. Three critical modifications were: (1) maintaining a $37^{\circ} \mathrm{C}$ temperature throughout screening and bioassay, (2) setting high standards of tissue selection to be used for bioassay, (3) quick manipulations during the bioassay. These alterations have eliminated the necessity of concentrating euglobulins from sera of CF carriers in order to detect a ciliary dyskinesia factor (CDF). In addition, the time necessary to detect a CDF response was reduced to 3 to 6 minutes in every serum sample from CF homozygotes and obligate heterozygotes. In general, sera from metachromasia negative CF affected and carrier subjects elicited a ciliotoxic response, as opposed to the more commonly observed ciliary dyskinesia seen in metachromasia positive CF individuals and their parents.

\section{Speculation}

It is our hypothesis that the CDF is a normal cellular product, and that the defect in $\mathrm{CF}$ is in the production or release of a factor inhibiting the CDF. 
Cystic fibrosis (CF) is an autosomal recessive disorder occurring in the Caucasian population. Mutations at more than one locus a re believed to cause $C F(4,6)$ perhaps distinguishable by the presence or absence of metachromasia in cultured fibroblasts.

The presence of material in the serum of $C F$ patients which produced dyskinesia in the normal beating pattern of rabbit tracheal cilia was first described by Spock (13). This ciliary dyskinesia factor (CDF) was found in sera of both CF and obligate heterozygotes for CF.

Although the factor was not demonstrable in the majority of normal subjects it is possible that it represents a normal product, which accumulates in individuals with the CF gene due to a deficiency of an enzyme or other inhibitor, which is present in normals in just sufficient quantity to completely inactivate $C D F$. This possibility is strengthened by the find ings of Rao et al, who have reported the lack of a trypsin-like activity in the saliva of CF patients (11) and the deficiency of kallikrein-like activity in their plasma (12)

In Spock's studies, it was necessaxy to concentrate the cuglobnlins from sera of most carriexs to demonstrate CDF by this bioassay. The advent of the oyster gill ciliary assay (2) provided a simpler method, inasmuch as it could detect the $C F$ serum factor in untreated sera from CF heterozygotes. This. assay was effective in differentiating $C F$ patients and obligate heterozygotes from normal, healthy subjects. A similar bioassay system has also been established by Besley (1), using fresh water mussels.

Although the non-mammalian bioassays of Bowman (2) and Besley (1) appear simplex and clearer than the Spock assay (13), the seasonal accessibility of these ciliary sources and the time required for each serum assay (30 to 40 minutes) limit, their use for routine screening. In contrast, the Spock bioassay procedure, utilizing rabbit trachea as the source of cilia, requires a shorter time for $C D F$ detection (5 to 10 minutes). In addition, the accessibility of rabbits and the practicality of the rabbit assay favored attempts at its more widespread utilization in spite of the necessity to concentrate sera from $C F$ carriers to detect $C D F$. Difficulties in establishing a reliable and reproducible rabbit tracheal as say have, however, been evident from previous reports $(3,10)$. In fact, a recent publication reports that sera from both $\mathrm{CF}$ and control subjects were markedly ciliotoxic, the reby putting in doubt the specificity of such CDF activity for CF (3)

The purpose of this report is to present details of our procedure for bioassay, as modified from the original Spock method (13). In our hands, untreated sera appear to reflect the presence of the CF gene in both carriers and affected subjects. In addition, our method requires only 3 to 6 minutes, and has been entirely accurate in detecting the CF trait from untreated sera of affected and obligate heterozygote individuals for $C F$, regardless of their metachromatic status. a) Samples

Clinically ascertained $C F$ patients and their parents were seen in the $C F$ specialty clinic of the Pediatric Out Patient Department of the Mount Sinai Hospital. Samples for assay are prepared by the following technique.

Approximately $20 \mathrm{ml}$ of clotted blood is obtained from each patient, centrifuged, and the serum transferred to plastic vials and frozen at $-20^{\circ} \mathrm{C}$. A portion of each serum is removed and used to prepare a euglobulin fraction by the following procedure:

(1) $\mathrm{CO}_{2}$ is bubbled through distilled water for 45 minutes at $4^{\circ} \mathrm{C}$.

(2) A 10:1 mixture of carbonated water:serum in a closed bottle is allowed to stand in an ice bath for 60 minutes, and centrifuged at 1700 RPM for 10 minutes at $4^{\circ} \mathrm{C}$. The precipitate is resuspended in carbonated water and recentrifuged.

(3) The precipitate is suspended in $0.5 \mathrm{ml}$ Ringer's solution for each $7.5 \mathrm{ml}$ serum initially used (Ringer's: pH 8.0 with $7.5 \% \mathrm{NaHCO}_{3}$ buffer), mixed well and frozen for future studies.

Fibroblasts from skin biopsies, and macrophages from peripheral blood of CF patients, obligate heterozygotes, and normal (control) subjects were grown in culture and examined for the presence of. metachromatic staining according to methods previously described $(5,8)$.

\section{b) Wash Medium (BME-W)}

Basal medium Eagle (BME) (Grand Island Biological Co.) supplemented by $50 \mathrm{U} / \mathrm{ml}$ penicillin and $50 \mathrm{mcg} / \mathrm{ml}$ streptomycin.

\section{c) Culture Medium (BME-C)}

$89 \%$ BME, $10 \%$ fetal calf serum, and $1 \% .200 \mathrm{mM} \mathrm{L}$-glutamine, with penicillin $(50 \mathrm{U} / \mathrm{ml})$ and streptomycin $(50 \mathrm{mcg} / \mathrm{ml})$. The $\mathrm{pH}$ for culture is adjusted to 7.2 to 7.4 with $5 \% \mathrm{CO}_{2}$.

\section{d) Culture of tracheal tissue}

Normal, white New Zealand rabbits ( 6 to $7 \mathrm{lbs}$ ) are used exclusively. Rabbits are killed by injection of air into an ear vein. Under aseptic conditions, the trachea is exposed and the mucosa is dissected from the underlying tissue. The trachea is then removed from just below the larynx to the carina, and immediately transferred to a $60 \times 15 \mathrm{~mm}$ Falcon petri dish containing $10 \mathrm{~mL}$ of $\mathrm{BME}-\mathrm{W}$ at $37^{\circ} \mathrm{C}$ and washed free of blood. The trachea is then transferred to another petri dish with $B M E-W$, where excess fat, connective tissue, and the esophagus are removed with sterile forceps and scissors. The clean trachea is transferred to a third petri dish with $B M E-W$ for transport to the tissue culture area. Once in the tissue culture area, the tissue is transferred to another petri dish with $B M E-W$ for 10 minutes. At this time, the trachea is cut along its dorsal ridge, stretched across a sterile \#14 rubber stopper (epithelium up) and fastened with needles. The epithelium is removed with a scalpel and is rinsed free of excessive mucus by three successive 10 minute washings in $B M E-W$ at $37^{\circ} \mathrm{C}$. This mucosal sheet is then transferred to a sterile watch glass contained in a petri dish, and approximately $1 \mathrm{ml}$ of BME-C is added. The mucosa is then minced 
with a scalpel and sets of 15 to 20 pieces are placed on the inside flat surface of Falcon $30 \mathrm{ml}$ culture flasks with the use of Pasteur pipettes. All culture flasks are then placed in a $37^{\circ} \mathrm{C}$ warm room and kept in a vertical position to allow drainage of excess medium and attachment of the mucosal pieces (60 to 90 minutes) to the culture surface of the vessel. After this time 2 to $3 \mathrm{ml}$ of $\mathrm{BME}-\mathrm{C}$ is added to each flask, the flasks are gassed with $5 \% \mathrm{CO}_{2}$ in air, and then left in a horizontal position until used for assay 2 to 3 days later.

\section{e) Bioassay}

The culture flasks containing tissue explants are henceforth kept exclusively in a $37^{\circ} \mathrm{C}$ warm room. All the screening of tissues and the bioassay micros copy are performed in the $37^{\circ} \mathrm{C}$ warm room. Explants are examined in the culture flask by light microscopy (100X) using an inverted Unitron microscope and tissue is selected for use by the following criteria: only those pieces with vigorously active cilia, minimal outgrowth and unobscured borders are used; in addition, only uniform, synchronously beating borders (ie., untraumatized), free of hemoglobin and mucous contamination are used. In general, entire flasks are eliminated from consideration if the $\mathrm{pH}$ of the culture medium is too high $(>7.4)$ or if mucus is found surrounding several of the pieces in any flask. Cultures were only used in the $\mathrm{pH}$ range of 6.8 to 7.4 .

Those pieces selected are removed as required for bioassay with a wooden applicator stick, and transferred to a glass slide upon which two drops of the serum or euglobulin to be tested has been placed. One or two pieces of tissue are used for each assay, and a coverslip is placed on the slide over the explants and sera. The assay is monitored through an inverted microscope with a $40 \mathrm{x}$ water-immersion objective. An appropriate border of cilia of each specimen is visualized within 15 to 30 seconds after the tissue is exposed to the serum. The ciliary action is observed during the succeeding 3 minutes. The result is recorded and, especially when negative, the observation is continued for an additional 3 minutes. Ciliary dyskinesia rather than ciliotoxicity (immobilization) is the only parameter used to characterize a positive test. Ciliary dyskinesia, as defined by Spock (13), consists of a disorganization of the regular wave-like appearance of the boundary of the beating cilia.

Each specimen was assayed three separate times and determination of any ciliary dyskinesia was made by two individual investigators, neither of whom was aware of the source of the sera.

Gradation of ciliary reaction was generally not considered of importance. However, subjectively a $\neq$ designation was used for slight dyskinesia, + for strong dyskinesia, and ++ for very marked asynchrony in the ciliary beat. In all cases of $t, t$, and $t+$, cilia displayed slight to strong dyskinesia within 3 or 6 minutes, and were readily distinguishable from those of a normal control (Negro) serum and euglobulin fraction. With each bioassay a negative control serum was tested initially to evaluate the vitality of the tissue. If no dyskinesia was observed with the control serum, results with known positive sera were always reliable.

\section{RESULTS}

Results of screening for CDF by the tracheal assay are presented in Table 1 . In no instance did the assay of the euglobulin fraction change the classification of a serum However, a number of sera from obligate heterozygotes displayed a \pm response at 3 minutes, which was intensified to t+ when their respective euglobulin fractions were used. Also, in some instances, a three minute assay of some heterozygote sera and euglobulin specimens demonstrated no ciliary dyskinesia. These samples, however, did produce ciliary dyskinesia after six minutes in the bioassay system, even when whole serum was used.

It was, however, observed on several occasions that certain sera and euglobulin specimens from heterozygotes were equally as strong as, or stronger than, specimens from $C F$ patients in causing ciliary dyskinesia. Therefore, any attempt to differentiate heterozygotes from affected homozygotes by this technique seemed fruitless.

All sera from the $12 \mathrm{CF}$ patients were positive for $\mathrm{CDF}$, as were the sera of all 35 obligate heterozygotes for CF (parents of patients). Of the four other relatives of $C F$ patients, at risk for carrying the gene for $C F$, three had positive sera indicating their heterozygote status. The 29 normal controls, picked for a negative family history of $\mathrm{CF}$, included two positive serum donors. Five of the 29 were Negroes, and these were all negative.

Two heterozygotes and one CF patient were found to be negative for metachromasia in their skin fibroblast and blood monocyte cultures. The sera of these individuals also caused ciliary dyskinesia. These three samples were unusual, however, in that they were ciliotoxic (caused complete cessation of ciliary motion) by six minutes in the bioassay system.

\section{DISCUSSION}

Our modification of the tracheal bioassay system are essentially those of temperature, tissue selection, and manipulation during the bioassay procedure. We feel that maintaining the temperature at $37^{\circ} \mathrm{C}$ during tracheal culture, explant screening and bioassay is critical in reducing tis sue traumatization and results in a greater percentage of utilizable explants with synchronously beating cilia. This permits us to set a high standard of tissue selection for use in the bioassay. Quick microscopic localization of an appropriate border of beating cilia at the start of each bioassay is a critical factor in allowing a meaningful and rapid $C D F$ detection.

The modified tracheal bioassay has resulted in an apparent increase in sensitivity of CDF detection. This permits assessment. of a CF affected or carrier status from serum alone without the need of concentrating euglobulins from the sera.

According to Lobeck (9) and Danks (7), the incidence of CF live births among Caucasians ranges from 1 in $l, 500$ to $l$ in 2,448 . Thus the CF heterozygote frequency has been estimated at 1 in 20 to 25 in the general population assuming that a single gene locus is responsible. Excluding the five Negro controls, we have ascertained 2 CF heterozygotes out of 24 total normals screened, which does not significantly differ from the expected heterozygote frequency.

\section{$\underline{\text { SUMMARY }}$}

Difficulties have previously been reported in establishing a reliable and reproducible rabbit tracheal bioassay for the detection of the serum cystic 
fibrosis (CF) trait. We have modified and standardized this assay to the extent that untreated sera from both $C F$ patients and obligate heterozygotes are positive. We have eliminated the necessity of concentrating euglobulins from sera of $C F$ carriers in order to detect a ciliary dyskinesia factor. In addition, serum from both metachromasia positive and negative varieties of CF demonstrate ciliary dyskinesia in our accelerated ( 3 to 6 minute) bioassay.

\section{REFERENCES and NOTES}

1. Besley G.T., Patrick A.D., Norman A.P.: Inhibition of the motility of gil cilia of Dreissensia by plasma of cystic fibrosis patients and their parents. J.Med. Genet. 6:278 (1969).

2. Bowman B.H., Lockhart L.H., McCombs M.L.: Oyster ciliary inhibition by cystic fibrosis factor. Science 164:325 (1969).

3. Cherry J.D., Roden V.I, Rejent A.J., Dorner R.W.: The inhibition of ciliary activity in tracheal organ cultures by sera from children with cystic fibrosis and control subjects. J.Ped. 79:937 (1971).

4. Childs B.: Fibrocystic disease of the pancreas; Report of the Eighteenth Ross Pediatric Research Conference, Ross Laboratories, Columbus, Ohio, pg. $87(1956)$.

5. Danes B.S., Bearn A.G.: A genetic cell marker in cystic fibrosis of the pancreas, Lancet $1: 1061$ (1968).

6. Danes B.S., Bearn A.G.: Cystic fibrosis of the pancreas, a study in cell culture. J. Exp. Med. 129:775 (1969).

7. Danks D.M., Allan J., Anderson C.M.: A genetic study of fibrocystic disease of the pancreas. Ann. Human Genet, 28:323 (1965).

8. Kraus I., et al: Metachromasia and assay for lysosomal enzymes in skin fibroblasts cultured from patients with cystic fibrosis and controls. Pediatrics 47:1010 (1971).

9. Lobeck C.C.: Cystic Fibrosis in Metabolic Basis of Inherited Disease, ed. Stanbury J.B., Wyngaarden J.B., Fredrickson D.S.; pp 1605 (1972), New York.

10. Posselt H., Bender S.: Heterozygote testing in cystic fibrosis. z. Kinderheilk 110:93 (1971).

11. Rao G.J., Nadler H.L.: Deficiency of trypsin-like activity in saliva of patients with cystic fibrosis. J.Ped. 80:573 (1972).

12. Rao G.J., Posner L.A., Nakler H.L.: Deficiency of kallikrein activity in plasma of patients with cystic fibrosis. Science $177: 610$ (1972).

13. Spock A., et al: Abnormal serum factor in patielits with cystic fibrosis of the pancreas. Pediat.Res. $1: 173$ (1967).

14. The Cystic Fibrosis Clinic is supported in part by a grant to Dr. R.F. Bonforte from the National Cystic Fibrosis Foundation.

15. Dr. E.J. Conod is a recipient of united States Public Health Service Predoctoral Training Grant No. HD00210 in Human Genetics.

16. Dr. K. Hirschorn was supported in part by United States Public Health Service Grants nos. AMI 3674 and HD02552, and by Genetics Center Grant no. GM19443. He is Career Scientist I-513 of the Health Research Council of the City of New York.

17. Dr. F.B. Kopel is deceased.

18. Requests for reprints should be addressed to: James H. Conover, Ph.D., Division of Medical Genetics, Department of Pediatrics, The Mount Sinai School of Medicine, looth st. and 5th Ave., New York, N.Y. 10029 (USA).

19. Accepted for publication February 14, 1973.

Table 1. Ciliary dyskinesia produced by serum, as observed by a 3 and 6 minute tracheal bioassay. 1

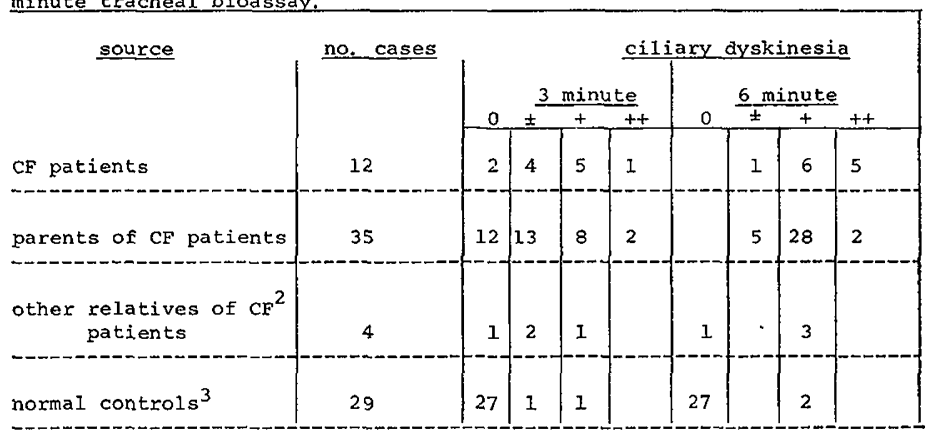

$I_{A 31}$ tests were read blindly by two observers. Concordance was $90-95 \%$ When disagreement occurred, samples were retested blindly by both observers until concordance was achieved.

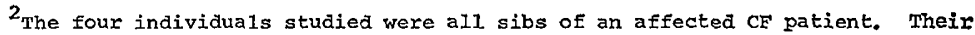
ages ranged from 16 to 25 . Their parents were also positive for CDF.

.3 Includes five Negro donors, all of whom were negative; all normal controls were adults, aged 21 to 45 . 